\title{
Model predictive control strategy of energy-water management in urban households
}

\author{
Evan M. Wanjiru*, Lijun Zhang, Xiaohua Xia \\ Centre of New Energy Systems, Department of Electrical, Electronic and Computer Engineering, University of \\ Pretoria, Pretoria 0002, South Africa
}

\begin{abstract}
The management of energy-water nexus in buildings is increasingly gaining attention among domestic end-users. In developing countries, potable water supply is unreliable due to increasing demand, forcing end-users to seek alternative strategies such as pumping and storage in rooftop tanks to reliably meet their water demand. However, this is at an increased cost of energy cost. In this paper, the open loop optimal control model and the closed-loop model predictive control (MPC) model, both with disturbances, are compared while minimizing the maintenance cost of the pump. The open loop optimal model is suitable in instances where only random disturbances due to measurement errors are present. However, in case the demand pattern changes for reasons such as occupancy change in the house, the closed-loop MPC model is suitable as it robustly minimizes the pumping cost while meeting the customer demand. Further, MPC proves its robustness as it is able to overcome the turnpike phenomenon. Each of these two models has their own strengths. The open loop model is cost effective and easy to implement for customers that have a steady demand pattern while the closed-loop MPC model is more robust against demand pattern changes and external disturbances. It is recommended that these two models are adopted according to the specific application.
\end{abstract}

Keywords: demand management, energy-water nexus, model predictive control, optimal control, time-of-use (TOU)

\begin{tabular}{|ll|}
\hline \multicolumn{2}{|l|}{ Nomenclature } \\
$A_{\text {tank }}$ & Cross-sectional area of the tank $\left(\mathrm{m}^{2}\right)$ \\
$D_{\text {tot }}$ & Total water demand $\left(\mathrm{m}^{3}\right)$ \\
$h(j)$ & Height of water in the tank during $j^{\text {th }}$ sampling interval $(\mathrm{m})$ \\
$h_{\min }$ & Minimum allowable height of water in the tank $(\mathrm{m})$ \\
$h_{\max }$ & Maximum allowable height of water in the tank $(\mathrm{m})$ \\
$J$ & Objective function (currency) \\
$k$ & Iteration index \\
\hline
\end{tabular}

*Corresponding author. Tel. +27 12420 6767; Fax +27 123625000.

Email address: murimev@gmail .com (Evan M. Wanjiru ) 


\begin{tabular}{|c|c|}
\hline$N$ & Total number of samples during the 24-h horizon \\
\hline$N_{p}$ & Total number of samples during the predicting horizon \\
\hline$p_{e}$ & Price of electricity using TOU tariff (currency/kWh) \\
\hline$p_{m}$ & Pump's motor rating $(k W)$ \\
\hline$p_{\text {off }}$ & Off-peak electricity price in the TOU tariff (currency/kWh) \\
\hline$p_{\text {peak }}$ & Peak electricity price in the TOU tariff (currency/kWh) \\
\hline$Q$ & The volumetric flow rate of water in one sampling interval $\left(\mathrm{m}^{3} / \mathrm{h}\right)$ \\
\hline TOU & Time-of-use tariff \\
\hline$t_{o}, t_{f}$ & Time in the first and final samples respectively \\
\hline$t_{s}$ and $j$ & Sampling period $(h)$ and $j^{\text {th }}$ sampling interval \\
\hline$u$ & State of the pump switch \\
\hline$V(j)$ & Volume of water in the tank in the $j^{\text {th }}$ sampling interval $\left(\mathrm{m}^{3}\right)$ \\
\hline$V_{\min }$ & Minimum allowable water volume in the tank $\left(\mathrm{m}^{3}\right)$ \\
\hline$V_{\max }$ & Maximum allowable water volume in the tank $\left(\mathrm{m}^{3}\right)$ \\
\hline$\omega$ & Weighting factor \\
\hline $\operatorname{Rand}(\mathrm{R})$ & South African currency $((1$ Rand $=0.065$ USD $)$, as at 23 March. 2016) \\
\hline
\end{tabular}

\section{Introduction}

The rising global population is increasingly putting pressure on the limited source of potable water [1], with $60 \%$ of the global demand estimated to be met by 2030 [2]. Actually, the world bank estimates that global water demand will increase at a projected rate ranging from $43 \%$ in North America to 283\% in Sub-Saharan Africa from 2005 to 2030 [3]. The impact of water insecurity is higher in the developing nations, like South Africa, due to high rate of economic development and subsequent rise in living standards [4]. Management of water demand in buildings through efficient technology and behavioural changes has strong entailment in reducing the demand for energy as well as conserving potable water supplies. Demand side management in buildings has mainly focused on energy, such as demand response [5], energy efficient building retrofitting [6, 7], renewable energy utilization [8] and control of efficient hot water systems [9]. Research has started to focus on the importance of demand management of energy-water nexus such as system-based framework for assessing the nexus in cities [10], nexus at a micro-component level using rain water tank [11], conservation in a building [12] and even in industries [13]. Although water supply in developed nations is reliable [14], the supply in developing nations is quite unreliable, and in some instances haphazard, where the end-users are forced to rely on other forms of supply like trucks [15]. This is the case in some cities in Nigeria, Ghana, Mexico and Indonesia [16].

South Africa, a semi-arid nation, is not only included in the worldwide trend of inefficient management of both energy and water but also has her demand far higher than the supply [17, 18]. The population growth rates and trends in socio-economic development indicate that South Africa's freshwater resources cannot sustain the current patterns of water consumption and discharge. At present, multiple regions in the country are experiencing water deficit [19], like KwaZulu-Natal 
province, whose severe water shortage has forced it to implement water rationing ${ }^{1}$. Similarly, the energy deficit has forced the power utility, ESKOM, to implement national load shedding program 2. Despite this dire situation, there is little information on household water consumption according to the department of water and sanitation [20]. A study by Jacobs et.al. [21, 22] found out that for the urban families with lawns and gardens, the most significant water end uses were garden irrigation $(37 \%)$, toilet $(21 \%)$, shower/bath (12\%) and clothes washing machine (9\%) of the total water consumption. This research compares well with other studies conducted in United States [23], Branz, New Zealand [24], Perth [25] and Melbourne in Australia [26].

The continual urbanization is increasing the adoption of decentralized water systems although there is still technological challenges in their operation [27]. Previous studies show that the problem with water supply in developing nations is forcing end-users to pump and store their water. Malik [28] looked at various coping strategies adopted by end-users in dealing with the uncertainties, unreliability and shortages of water supply in India. End users are forced to have various water storage means such as overhead tanks and having containers in the house. They are also forced to change their water use pattern highly inconveniencing them. Vieira and Ghisi [29] conducted a study on energy-water nexus for low income houses in Brazil and found out that the diseconomies of scale associated with pumping and storage increased the energy intensity for water services. Another study on residential rain water tanks showed that pumps increase the energy intensity and the consequent bills to the end-users [11]. Research on pump scheduling has mostly focused on industrial [30], agricultural [31] and large scale municipal pumping [32]. However, for domestic users, pumping takes place with no consideration to the peak power consumption negatively affecting the grid and increasing electricity bills incurred by the end-users.

This introductory paper reports the first attempt to design novel, practical and economically attractive open loop optimal control and closed-loop model predictive control (MPC) strategies for pumping and storing water in a tank to meet the hourly water demand in a house subject to the time-of-use (TOU) electricity tariff. These control models ensure energy efficiency in cases where either there is water rationing or the water supply is always there but it has low pressure and cannot therefore be used directly in the house. We consider the latter case in this paper. The controls are superior to the classical control methods such as proportional-integral-derivative (PID) controls. PID controllers have low accuracy in processes which are either non-linear or have a large time delay [33]. Further, PID controllers only handle effectively single input-single output (SISO) systems. However, MPC can handle multiple input-multiple output (MIMO) systems, deal with constraints [34], has higher accuracy, robustness against disturbances and has the ability to predict the future behaviour of the plant [35]. It nonetheless comes at a higher computational cost [36]. The application of MPC and PID to water pumping and level control systems have been studied by many researches, such as [37] and [38], who concluded that MPC is better than PID in terms of Rise time, Settling time and maximum overshoot. It also intrinsically and quickly compensates for disturbances in the system [39]. The aim of the controls presented in this study is to optimally operate the pump in the pump-storage scheme such that the customer's water demand can be satisfied with minimum electricity cost and maintenance cost of the pump. Two models, namely open

\footnotetext{
${ }^{1}$ Department of Water and Sanitation www.dwa.gov.za/default .aspx

2 http://loadshedding.eskom.co.za/
} 
loop control and closed-loop MPC control, are introduced to cater for different application requirements. The open loop control is easy to implement and more cost effective and is more suitable for applications where the water demand pattern is known to be relatively stable. However, in cases where the demand pattern is known to be fluctuating in a way that is difficult to predict and/or the external disturbances to the implementation of the control system is of significant impact, the closed-loop control must be adopted. Although it has the ability to robustly control the system under the aforementioned fluctuating demand and disturbances, it requires installation of additional monitoring devices to the system such as water level measurement of the tank, which increases the cost and complexity of the control system.

\section{Model layout and formulation}

\subsection{Schematic model layout}

The increasing water demand due to increasing population and urbanization is causing inadequate supply to the end-users. The situation is worsened by the fact that the existing supply infrastructure is not expanding proportionately to the demand forcing end-users to resolve to alternative measures like pumping and storing the water [40]. Figure 1] shows the schematic diagram

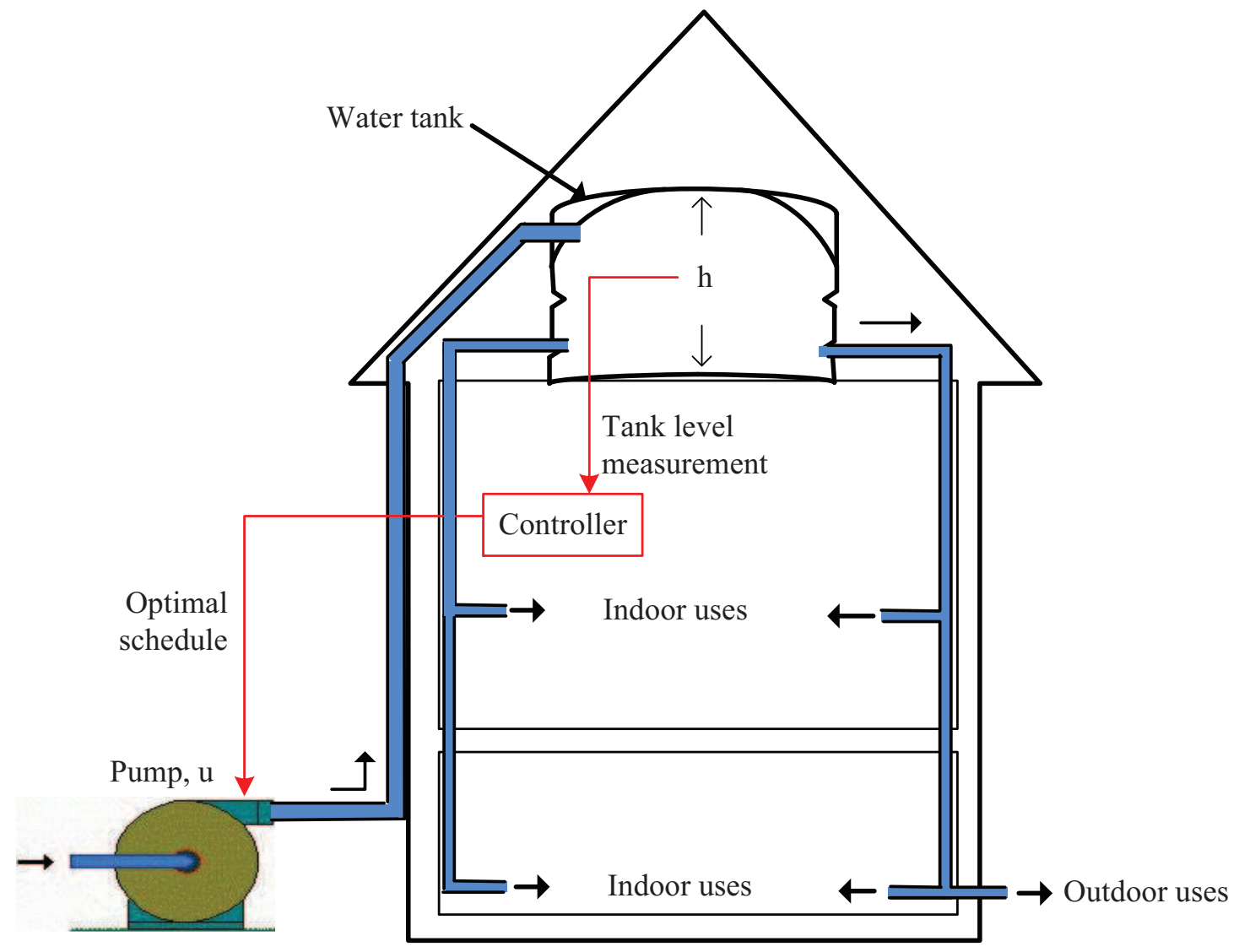

Figure 1: Schematic of domestic water supply system with pumping and storage. 
of the water supplying system in a house where water has to be pumped and stored for later use. A fixed speed pump with a switch $(u)$ pumps the water to a rooftop storage tank whose size is restricted to the space available. From the tank, water flows by gravity with the required pressure to various end uses. Two pump control models are considered in this paper. First, an open loop control model is developed by using the predicted diurnal water demand. Secondly, a closed-loop MPC model is developed whereby, the level of water in the tank is measured using level sensors. This is used as the feedback signal to the controller, which then optimises the schedule for pumping to meet the demand.

\subsection{Open loop optimal control model}

This model seeks to minimize the cost of energy used in pumping water to the tank while simultaneously minimizing the maintenance cost of the pump and effectively maximizing its life cycle. It is assumed that water is always flowing in the municipal pipe albeit at low pressure and there is no water rationing. In case of water rationing, the same formulation is applicable, but the controller would have the information on when the water will be present in order to start pumping. In this paper, we consider an evaluation period of one day, or a full operation cycle of 24 $\mathrm{h}$, from 0 to hour 24 with a sampling period, $t_{s}$, of $10 \mathrm{~min}$. This leads to a total number of samples $N=\frac{24}{t_{s}}=144$. Therefore, to minimize cost of energy used in pumping the water, the objective function is,

$$
J=\sum_{j=1}^{N} p_{m} t_{s} p_{e}(j) u(j) .
$$

where $p_{m}$ is the pump rating, $p_{e}(j)$ is the cost of electricity in the $j^{\text {th }}$ sampling interval using the time-of-use tariff and $u(j)$ is the on/off status of the pump during the $j^{\text {th }}$ sampling interval. This objective is subject to the constraints discussed below.

\subsubsection{Capacity of the water tank}

The dynamics of the volume of water in the tank can be expressed in discrete-time domain by a first order differential equation as follows:

$$
V(j+1)=V(j)+Q t_{s} u(j)-D_{t o t}(j),
$$

where $Q$ is the flow rate of the water through the pump in $m^{3} / h$ and $D_{t o t}(j)$ is the total water demand in the $j^{\text {th }}$ sampling interval in $m^{3}$. Expressing this volume in terms of the initial volume $V(0)$ in the tank using recurrence manipulation gives,

$$
V(j)=V(0)+\sum_{i=1}^{j}\left(Q t_{s} u(i)-D_{t o t}(i)\right), \quad(1 \leq j \leq N) .
$$

The water pumped into the tank must not spill from the tank as it would lead to wastage of water and damage the house's ceiling. Similarly, the tank should not be completely empty in order to 
prevent air from getting into the pipes [41], as well as to avoid inconveniencing the end-users [42]. Therefore, the amount of water in the tank is restricted by the tank's dimensions as follows

$$
V_{\text {min }} \leq V(0)+\sum_{i=1}^{j}\left(Q t_{s} u(i)-D_{\text {tot }}(i)\right) \leq V_{\text {max }}, \quad(1 \leq j \leq N) .
$$

where $V_{\min }$ and $V_{\max }$ are the minimum and maximum allowable volumes of the water in the tank respectively.

\subsubsection{Tank's terminal constraint}

It is desired that at the end of the horizon, a certain volume, $V_{f}$, of water is left in the tank. From the state equation (2), then the volume of water in the tank during the last sampling interval is;

$$
V_{f}=V(N)=V(0)+\sum_{j=1}^{N}\left(Q t_{s} u(j)-D_{t o t}(j)\right)
$$

\subsubsection{Pump maintenance cost}

Minimum energy cost may be achieved by frequently switching the pump on and off during the control period. Unfortunately, this frequent switching of the pump increases the pump maintenance cost due to high wear [43]. The number of pump switching can be used as an alternative variable for measuring the pump maintenance cost [32].

Even though maintenance cost has not been considered in some studies [44], common methods used to minimize it are; switching the pump for a pre-set minimum duration [45], and restricting the maximum number of times a pump can switch during the control period [46]. These methods, nonetheless, do not optimally control the pump while minimizing the maintenance cost. Actually, if the water demand rises, the optimal solution would easily become infeasible as the controller is restricted on the number of times it can switch instead of adapting accordingly. To overcome this, the Pretoria method by Mathaba et al. [47] introduces an auxiliary variable $s(j)$ represented by a value 1 whenever the pump's state is changed from off to on. This auxiliary variable is optimally determined by the following optimization problem.

$$
\min \sum_{j=1}^{N} s(j)
$$

constrained by

$$
\begin{gathered}
u(1)-s(1) \leq 0, \\
u(j)-u(j-1)-s(j) \leq 0,
\end{gathered}
$$

with $s(j) \in\{0,1\}$. The inequality $7 \mathrm{a}$ initialises the auxiliary variable as the initial status of $u$ while the inequality (7b) favours the control that involves less switching. Using this method, the overall objective that simultaneously minimizes the cost of energy and maintenance is

$$
J=\sum_{j=1}^{N}\left((1-\omega) p_{m} t_{s} p_{e}(j) u(j)+\omega s(j)\right)
$$

where $\omega$ is a weighting factor. 


\subsubsection{Pump's switch}

This paper focuses on fixed speed pumps which are commonly used in water pumping in urban houses. This type of pump is ideal for the current task, unlike the more expensive variable speed drives, because the water just needs to be pumped and stored. Therefore, under optimal operation, the pump should not require additional investments on flow rate adjustment devices such as valves and variable speed drives [30]. The pump controller only switches the pump on/off such that it can be modelled as a switch control problem, where

$$
u(j) \in\{0,1\}, \quad(1 \leq j \leq N) .
$$

\subsection{Algorithm for solving the open loop optimization problem}

The objective function (8) is solved using the following canonical form [48].

$$
\min f^{T} X
$$

subject to

$$
\left\{\begin{array}{l}
A X \leq b \text { (linear inequality constraint) } \\
A_{e q} X=b_{e q} \text { (linear equality constraint) } \\
L_{B} \leq X \leq U_{B} \text { (lower and upper bounds) }
\end{array}\right.
$$

Here, vector $X$ contains the control variables, which are the pump switch $u(j)$ and the auxiliary variable $s(j)$ used to minimize the frequency of pump switching. Thus,

$$
X=\left[\begin{array}{lllll}
u(1), & \ldots, & u(N), \quad s(1), \quad \ldots, & s(N)
\end{array}\right]_{2 N \times 1}^{T} .
$$

The vector $f^{T}$ in the canonical form $(10)$ can be obtained from the objective function $(8)$ as

$$
f^{T}=\left[\begin{array}{llllll}
(1-\omega) p_{m} t_{s} p_{e}(1) & \ldots & (1-\omega) p_{m} t_{s} p_{e}(N) & \omega & \ldots & \omega
\end{array}\right]_{1 \times 2 N} .
$$

The linear inequality constraint (4) can be transformed into

$$
\begin{aligned}
A_{1} X & \leq b_{1}, \\
-A_{1} X & \leq b_{2},
\end{aligned}
$$

where,

$$
\left.\begin{array}{c}
A_{1}=\left[\begin{array}{ccccccc}
-t_{s} Q & 0 & \ldots & 0 & 0 & \ldots & 0 \\
-t_{s} Q & -t_{s} Q & \ldots & 0 & 0 & \ldots & 0 \\
\vdots & \vdots & \ddots & \vdots & \vdots & \ddots & \vdots \\
-t_{s} Q & -t_{s} Q & \ldots & -t_{s} Q & 0 & \ldots & 0
\end{array}\right]_{N \times 2 N} \\
-D_{t o t}(1)-\left(V_{\min }-V(0)\right) \\
-\left(D_{t o t}(1)+D_{t o t}(2)\right)-\left(V_{\min }-V(0)\right) \\
\vdots \\
-\left(D_{t o t}(1)+D_{t o t}(2)+\ldots+D_{t o t}(N)\right)-\left(V_{\min }-V(0)\right)
\end{array}\right]_{N \times 1}
$$


and

$$
b_{2}=\left[\begin{array}{c}
D_{t o t}(1)+\left(V_{\text {min }}-V(0)\right) \\
\left(D_{t o t}(1)+D_{t o t}(2)\right)+\left(V_{\text {min }}-V(0)\right) \\
\vdots \\
\left(D_{t o t}(1)+D_{t o t}(2)+\ldots+D_{t o t}(N)\right)+\left(V_{\text {min }}-V(0)\right)
\end{array}\right]_{N \times 1}
$$

Again, the linear inequalities (7a) and (7b) can be represented by

$$
A_{3} X \leq b_{3},
$$

where

$$
\begin{aligned}
A_{3} & =\left[\begin{array}{ccccccccccc}
1 & 0 & 0 & \ldots & 0 & 0 & -1 & 0 & 0 & \ldots & 0 \\
-1 & 1 & 0 & \ldots & 0 & 0 & 0 & -1 & 0 & \ldots & 0 \\
0 & -1 & 1 & \ldots & 0 & 0 & 0 & 0 & -1 & \ldots & 0 \\
\vdots & \vdots & \vdots & \ddots & \ddots & \vdots & \vdots & \vdots & \vdots & \ddots & \vdots \\
0 & 0 & 0 & \ldots & -1 & 1 & 0 & 0 & 0 & \ldots & -1
\end{array}\right]_{N \times 2 N}, \\
b_{3} & =\left[\begin{array}{lllll}
0 & 0 & 0 & \ldots & 0
\end{array}\right]_{1 \times N}^{T} .
\end{aligned}
$$

Then, the canonical linear inequality constraint in (11) becomes

$$
\left[\begin{array}{c}
A_{1} \\
-A_{1} \\
A_{3}
\end{array}\right]_{3 N \times 2 N} X \leq\left[\begin{array}{l}
b_{1} \\
b_{2} \\
b_{3}
\end{array}\right]_{3 N \times 1}
$$

In similar veins, linear equality constraint (5) can be written as follows;

$$
A_{e q} X=b_{e q}
$$

where

$$
A_{e q}=\left[\begin{array}{ccc:ccc}
0 & \ldots & 0 & 0 & \ldots & 0 \\
\vdots & \ddots & \vdots & \vdots & \ddots & \vdots \\
0 & \ldots & 0 & 0 & \ldots & 0 \\
\hdashline t_{s} \bar{Q} & \ldots & t_{s} Q & 0 & \ldots & 0
\end{array}\right]_{N \times 2 N}
$$

and

$$
b_{e q}=\left[\begin{array}{c}
0 \\
\vdots \\
0 \\
\hdashline\left(V_{f}-V(0)+\left(D_{t o t}(1)+\ldots+D_{t o t}(N)\right)\right.
\end{array}\right]_{N \times 1} .
$$

Finally, the canonical lower and upper bounds in (11) are written as

$$
L_{B}=\left[\begin{array}{llllll}
0, & \ldots, & 0, & 0, & \ldots, & 0
\end{array}\right]_{2 N \times 1}^{T} \quad U_{B}=\left[\begin{array}{llllll}
1, & \ldots, & 1, & 1, & \ldots, & 1
\end{array}\right]_{2 N \times 1}^{T}
$$


This binary linear optimization problem is solved using the SCIP solver, available in the Matlab interface OPTI toolbox. SCIP is currently one of the fastest non-commercial solvers for mixed integer (linear and non-linear) programming [49].

The open loop controller is able to provide the optimal pump control schedule in vector $X$ throughout the whole control horizon using the predicted water demand. The results are discussed later in the paper.

\subsection{Closed-loop MPC model}

Closed-loop MPC method uses the explicit model of the plant to optimize the future plant behaviour [50]. The current control action is obtained by solving on-line a finite open loop optimal control problem using the current state of the plant as the initial state. The optimization produces an optimal control sequence, but only the first control step is applied to the plant [51]. This ability to compute the control law on-line is a huge benefit of MPC over the conventional control in instances where off line computation of the control law is difficult [35].

Taking measurements and feeding them back to the controller provides stability and robustness against disturbances and inaccurate system modelling [52]. In this model, volume of water in the tank is measured using sensors, and then fed back to the controller. The tank considered is assumed to be cylindrical, such that level sensors, which are the most economical and easy to implement, can be used to provide the height of the water in the tank. The tank dynamic equation (2) can then be modified to give the height of the water, $h$, in the tank as;

$$
h(j+1)=h(j)+\frac{1}{A_{\text {tank }}}\left(Q t_{s} u(j)-D_{\text {tot }}(j)\right) .
$$

Following the idea of MPC, the objective function (8), can now be modified to,

$$
J_{m p c}=\sum_{j=k}^{k+N_{c}-1}\left((1-\omega) p_{m} t_{s} p_{e}(j) u(j \mid k)+\omega s(j \mid k)\right),
$$

where $N_{c}$ is the control horizon, $u(j \mid k)$ and $s(j \mid k)$ are the predicted values at the $j^{\text {th }}$ sampling interval based on the information available at time $k$. Although common MPC optimization problems include both the predicting $\left(N_{p}\right)$ and control $\left(N_{c}\right)$ horizons, such that $N_{c} \leq N_{p}$, this MPC problem does not include $N_{p}$ because the above objective function does not have the state variable, $h(j)$, included.

In the optimization algorithm, the control vector, $X^{m p c}$ will still contain the pump switch $u(j)$ and the auxiliary variable $s(j)$ such that

$$
X^{m p c}=\left[u(k \mid k), u(k+1 \mid k), \ldots, u\left(k+N_{c}-1\right), s(k \mid k), s(k+1 \mid k), \ldots, s\left(k+N_{c}-1\right)\right]_{2 N_{c} \times 1}^{T}
$$

Therefore, the vector $f^{T}$ in the objective function's canonical form 110 can be derived form objective function 26) as,

$$
\begin{array}{r}
f^{T}=\left[(1-\omega) p_{m} t_{s} p_{e}(k),(1-\omega) p_{m} t_{s} p_{e}(k+1), \quad \ldots, \quad(1-\omega) p_{m} t_{s} p_{e}\left(k+N_{c}-1\right),\right. \\
\omega, \quad \ldots, \quad \omega]_{1 \times 2 N_{c}}
\end{array}
$$


This objective function is minimized subject to the same constraints modelled in section 2.2 albeit with the following adjustments.

(1) Tank's capacity: The volume of the water in the tank within the control horizon, $N_{c}$, is constrained by the tank's capacity between the maximum and minimum allowable water volume. Since the tank is assumed to be cylindrical, and the level sensor will give the height of water in the tank, then,

$$
h_{\text {min }} \leq h(k)+\sum_{i=k}^{j} \frac{1}{A_{\text {tank }}}\left(Q t_{s} u(i \mid k)-D_{\text {tot }}(i)\right) \leq h_{\text {max }}, \quad k \leq j \leq k+N_{c}-1
$$

where $h(k)$ is the measured height of the water in the tank at time $k$ having a cross-sectional area $A_{\text {tank }}$ while, $h_{\min }$ and $h_{\max }$ are the minimum and maximum allowed water heights in the tank respectively such that $h_{\text {min }}=\frac{V_{\min }}{A_{\text {tank }}}$ and $h_{\text {max }}=\frac{V_{\max }}{A_{\text {tank }}}$. In the algorithm, the linear inequality can be transformed into,

$$
\begin{aligned}
A_{1}^{m p c} X^{m p c} & \leq b_{1}^{m p c}, \\
-A_{1}^{m p c} X^{m p c} & \leq b_{2}^{m p c},
\end{aligned}
$$

where,

$$
\begin{gathered}
A_{1}^{m p c}=\left[\begin{array}{ccccccc}
-t_{s} Q & 0 & \ldots & 0 & 0 & \ldots & 0 \\
-t_{s} Q & -t_{s} Q & \ldots & 0 & 0 & \ldots & 0 \\
\vdots & \vdots & \ddots & \vdots & \vdots & \ddots & \vdots \\
-t_{s} Q & -t_{s} Q & \ldots & -t_{s} Q & 0 & \ldots & 0
\end{array}\right]_{N_{c} \times 2 N_{c}}, \\
b_{1}^{m p c}=\left[\begin{array}{c}
-D_{\text {tot }}(k)-A_{\text {tank }}\left(h_{\min }-h(k)\right) \\
-\left(D_{\text {tot }}(k)+D_{\text {tot }}(k+1)\right)-A_{\text {tank }}\left(h_{\min }-h(k)\right) \\
\vdots \\
-\left(D_{t o t}(k)+D_{t o t}(k+1)+\ldots+D_{t o t}\left(k+N_{c}-1\right)\right)-A_{\text {tank }}\left(h_{\min }-h(k)\right)
\end{array}\right]_{N_{c} \times 1},
\end{gathered}
$$

and

$$
b_{2}^{m p c}=\left[\begin{array}{c}
D_{\text {tot }}(k)+A_{\text {tank }}\left(h_{\text {max }}-h(k)\right) \\
\left(D_{\text {tot }}(k)+D_{\text {tot }}(k+1)\right)+A_{\text {tank }}\left(h_{\text {max }}-h(k)\right) \\
\vdots \\
\left.\left(D_{\text {tot }}(k)+D_{t o t}(k+1)+\ldots+D_{\text {tot }}\left(k+N_{c}-1\right)\right)+A_{\text {tank }}\left(h_{\max }-h(k)\right)\right)
\end{array}\right]_{N_{c} \times 1}
$$

(2) Pump switching constraints: The constraint minimizing the switching frequency of the pump now becomes,

$$
u(1 \mid k)-s(1 \mid k) \leq 0
$$




$$
u(j \mid k)-u(j-1 \mid k)-s(j \mid k) \leq 0,
$$

with $s(j \mid k) \in\{0,1\}$. The inequality constraint $34 \mathrm{a}$ ) initialises the auxiliary variable as the initial status of $u$ based on information available at time $k$ while the inequality (34b) favours the control involving less switching between adjacent sampling intervals based on information available at time $k$. The constraints can be represented by,

$$
A_{3}^{m p c} X^{m p c} \leq b_{3}^{m p c}
$$

where

$$
\begin{aligned}
A_{3}^{m p c} & =\left[\begin{array}{ccccccccccc}
1 & 0 & 0 & \ldots & 0 & 0 & -1 & 0 & 0 & \ldots & 0 \\
-1 & 1 & 0 & \ldots & 0 & 0 & 0 & -1 & 0 & \ldots & 0 \\
0 & -1 & 1 & \ldots & 0 & 0 & 0 & 0 & -1 & \ldots & 0 \\
\vdots & \vdots & \vdots & \ddots & \ddots & \vdots & \vdots & \vdots & \vdots & \ddots & \vdots \\
0 & 0 & 0 & \ldots & -1 & 1 & 0 & 0 & 0 & \ldots & -1
\end{array}\right]_{N_{c} \times 2 N_{c}} \\
b_{3}^{m p c} & =\left[\begin{array}{llllll}
0 & 0 & 0 & \ldots & 0
\end{array}\right]_{N_{c} \times 1}^{T} .
\end{aligned}
$$

Therefore, the linear inequality constraint (11) now becomes

$$
\left[\begin{array}{l}
A_{1}^{m p c} \\
-A_{1}^{m p c} \\
A_{3}^{m p c}
\end{array}\right]_{3 N_{c} \times 2 N_{c}} X^{m p c} \leq\left[\begin{array}{l}
b_{1}^{m p c} \\
b_{2}^{m p c} \\
b_{3}^{m p c}
\end{array}\right]_{3 N \times 1}
$$

(3) Terminal constraint: At the end of the 24-h horizon, the height of water in the tank should be $h_{f}$ such that,

$$
h_{f}=h(k)+\sum_{j=k}^{N-k+1} \frac{1}{A_{\text {tank }}}\left(Q t_{s} u(j \mid k)-D_{\text {tot }}(j)\right)
$$

In the algorithm, this constraint is written as the canonical linear equality constraint in (11) as,

where

$$
A_{e q}^{m p c} X^{m p c}=b_{e q}^{m p c},
$$

$$
A_{e q}^{m p c}=\left[\begin{array}{ccc:ccc}
0 & \ldots & 0 & 0 & \ldots & 0 \\
\vdots & \ddots & \vdots & \vdots & \ddots & \vdots \\
0 & \ldots & 0 & 0 & \ldots & 0 \\
\hdashline t_{s} \bar{Q} & \ldots & \bar{t}_{s} \bar{Q} & 0 & \ldots & 0
\end{array}\right]_{N_{c} \times 2 N_{c}}
$$

and

$$
b_{e q}^{m p c}=\left[\begin{array}{c}
0 \\
\vdots \\
0 \\
\hdashline-\left(h_{f}-h(k)+\left(D_{t o t}(k)+\ldots+D_{t o t}(N-1)\right)\right.
\end{array}\right]_{N_{c} \times 1}
$$


In this case, $N_{c}$ is evolving all the time as $N_{c}=N-k+1$.

(4) Upper and lower bounds: The on/off control of the pump is still modelled as switch control problem such that,

$$
u(j \mid k) \in\{0,1\} .
$$

In the canonical lower and upper bounds in (11), they are written as

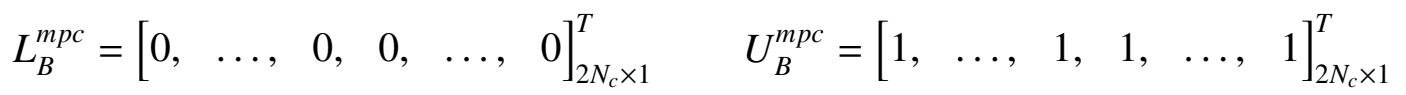

The open loop optimal control problem (26) is solved, using SCIP solver in the Matlab interface OPTI toolbox, during each iteration over the finite 24-h horizon. Although, in MPC, the optimal vector, $X$ contains the controls, using the principle of the receding horizon control, only the first element in the control vector $X^{m p c}$ is implemented after each iteration, ignoring the rest of the elements [53]. The state of the plant (water level in the tank, $h(j)$ ) is also measured. At the next iteration, $k+1$, the objective function and the constraints are updated while $h(k)$ is taken as the initial state and the process of optimization is carried out in real time over the new control horizon $\left(N_{c}=N-k+1\right)$ to give the receding horizon control law.

\section{General data}

\subsection{Case study}

A maisonette house in a gated community in Tshwane, South Africa was chosen for this study. The house, with five occupants, has the following end-uses; two showers, a bath tub, two toilets, two hand taps, a kitchen tap, a clothes washing machine, a dish washer, a grass lawn and an electric water heater for all the hot water demand. The water from the municipal supply requires pumping and storage due to its low pressure. The pump is currently controlled by two sensors in the tank such that when the water level is low, the pump is switched on until the tank is full regardless of the cost of electricity using the TOU tariff. This is used as the baseline in this paper. The water flows from the storage tank to the various end-uses by gravity. Jojo's $1000 l$ cylindrical water tank with a diameter and height of 1.1 and $1.3 \mathrm{~m}$ respectively is used and the lower and upper levels of the water in the tank are set as 0.12 and $1 \mathrm{~m}$, respectively to avoid spilling the water from the tank as well as running it completely empty. In addition, Grundfos Leader EBS 800 pump ${ }^{4}$ rated at $0.8 \mathrm{~kW}$ with a flow rate of $0.9 \mathrm{~m}^{3} / \mathrm{h}$ at a maximum head of about $30 \mathrm{~m}$ is used. This pump is specifically designed for pressurised water supply in domestic and other small scale applications.

The water demand in the house was measured every hour by placing a digital flow meter connected to a data logger, for a period of one week. From the measurements carried out, the average hourly water demand is shown in Figure 2. The demand has the highest peak in the morning between 7 and $10 \mathrm{AM}$. There is also another peak in the evening from 5 to around 9 PM. The morning peak is attributed to people waking up and preparing to go to work or school with the highest end-use demand being showering and the clothes washer. Likewise, the evening demand

\footnotetext{
${ }^{3}$ Water tank www.jojotanks.co.za/

$4_{\text {www.davisandshirtliff.com/categories/product/104-ebs-800 }}$
} 


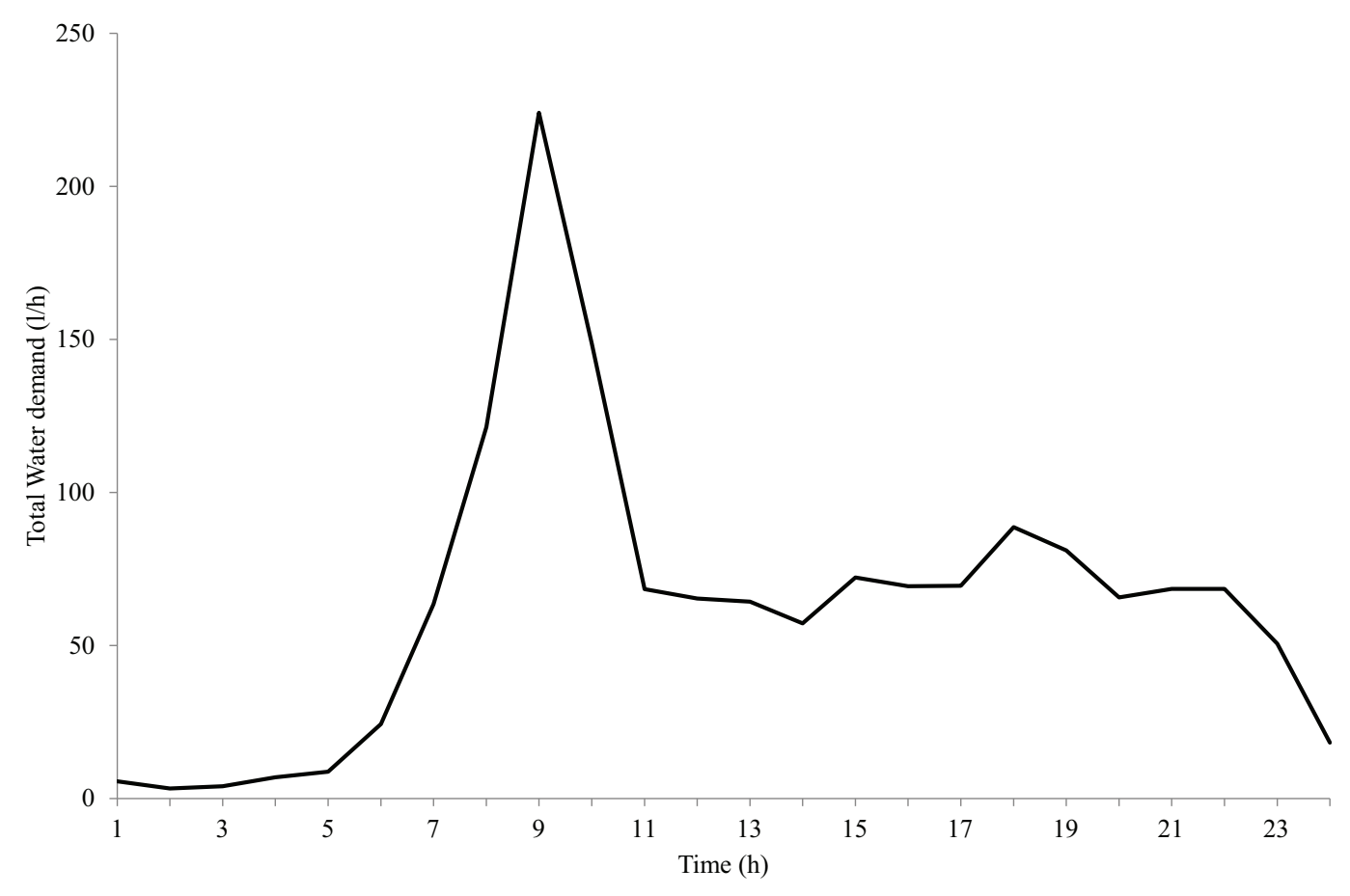

Figure 2: Baseline average hourly water demand.

is attributed to people getting back home from work. The consumption during the day is attributed to those at home during the day. Although this hourly demand is similar to the one obtained by Willis et.al. [54], the extensive conservation awareness and measures carried out in their study area made the daily water consumption to be less than what was obtained in our study.

\subsection{Time-of-use electricity tariff}

The TOU tariff is commonly used globally [55] and it can vary by time of day, day of week and season [56]. Eskom's TOU Homeflex structure ${ }^{5}$ for residential consumers given below is used for the house.

$$
p_{e}(t)=\left\{\begin{array}{lll}
p_{\text {off }}=0.5510 & R / K w h & \text { if } t \in[0,6] \cup[10,18] \cup[20,24] \\
p_{\text {peak }}=1.7487 & R / K w h & \text { if } t \in[7,10] \cup[18,20]
\end{array}\right.
$$

where $p_{e}(t)$ is the hourly price of electricity, $p_{\text {off }}$ is the off peak price, $p_{\text {peak }}$ is the peak time price, $R$ is the South African currency, Rand, and $t$ is the time of day in hours. The tariff has five charge components as service charge, network charge, environmental levy, peak charge and off-peak charges [57].

\footnotetext{
${ }^{5}$ Eskom tariffs and charges booklet 2011/2012. www . eskom . co.za
} 


\section{Simulation results and discussion}

\subsection{Control models without disturbance}

This section compares both the open and closed-loop models with the intention of showing that the closed-loop MPC model is just as effective as the open loop optimal model when there are no disturbances, system inaccuracies or plant failures. In addition, the legend representing peak time and off-peak time for the TOU tariff is the same throughout the paper.

It can be seen from Figure 3 that all the pump schedules take place during the off-peak period, effectively shifting the load from the peak time. Figures $3 \mathrm{a}$ and $3 \mathrm{~b}$ show the results without

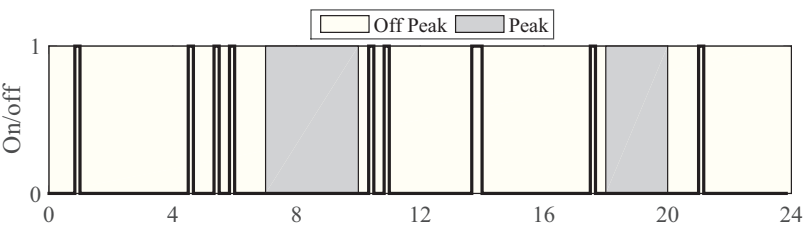

(a) Open loop optimal, no maintenance

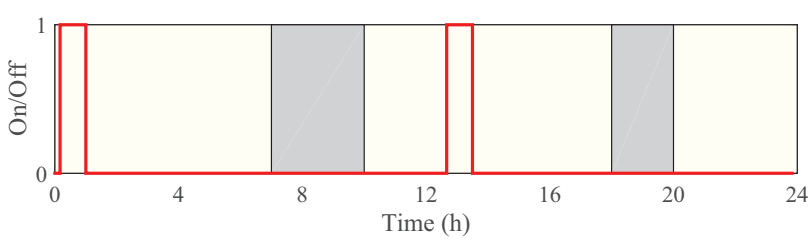

(c) Open loop, maintenance

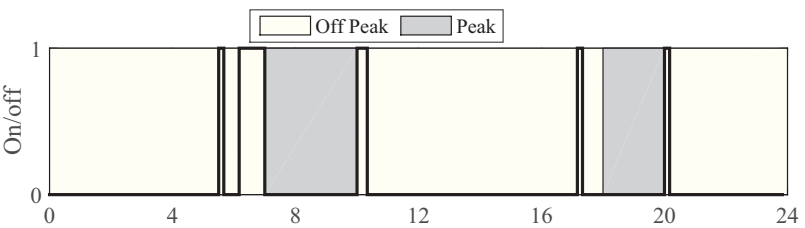

(b) MPC, no maintenance

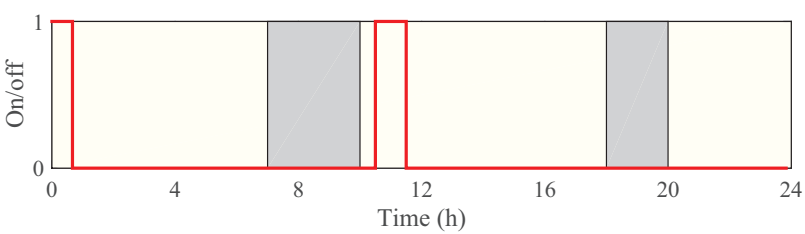

(d) MPC, maintenance

Figure 3: Comparison of both open loop and MPC with the effect of minimization of the maintenance cost.

considering the pump's maintenance cost. The frequent switching of the pump is undesired, as it leads to high wear and tear of the pump's motor as it tries to overcome the dead weight caused by the stationary load (water), hence increasing the maintenance cost. Although not accounted for in this model, the frequent starting of the pump could also lead to higher energy costs due to the high start-up current required in overcoming the dead weight. Therefore, the strategy employed to minimize the switching frequency and effectively minimize the maintenance cost works both in open loop model (Figure 3c) as well as the MPC model (Figure 3d). All the four models, however, incur the same cost of energy proving that both the open loop and MPC models are effective with no disturbances.

The variation of the state variable, that is, water level in the tank $(h(j))$ due to the models in Figure 3 is shown in Figure 4. It can be seen that none of the models violated the constraints for the tank. In the optimal open loop model without consideration of the maintenance cost (Figure 3a), the pump switches at 00:50 the first time for a duration of 10 minutes only, causing the water level in the tank to increase in the tank. The pump switches on frequently between 04:30-06:00 hours causing another rise of the water level in the tank to a height of $0.75 \mathrm{~m}$. The pump is then switched off through the peak time where the water level in the tank declines to $0.135 \mathrm{~m}$ due to the water demand in the house. The controller then senses that the water level is declining and switches on the pump at 10:20, again frequently with the longest duration being $20 \mathrm{~min}$ causing the water level in the tank to vary. Similarly, the MPC schedule with no maintenance cost (Figure 3b) frequently 


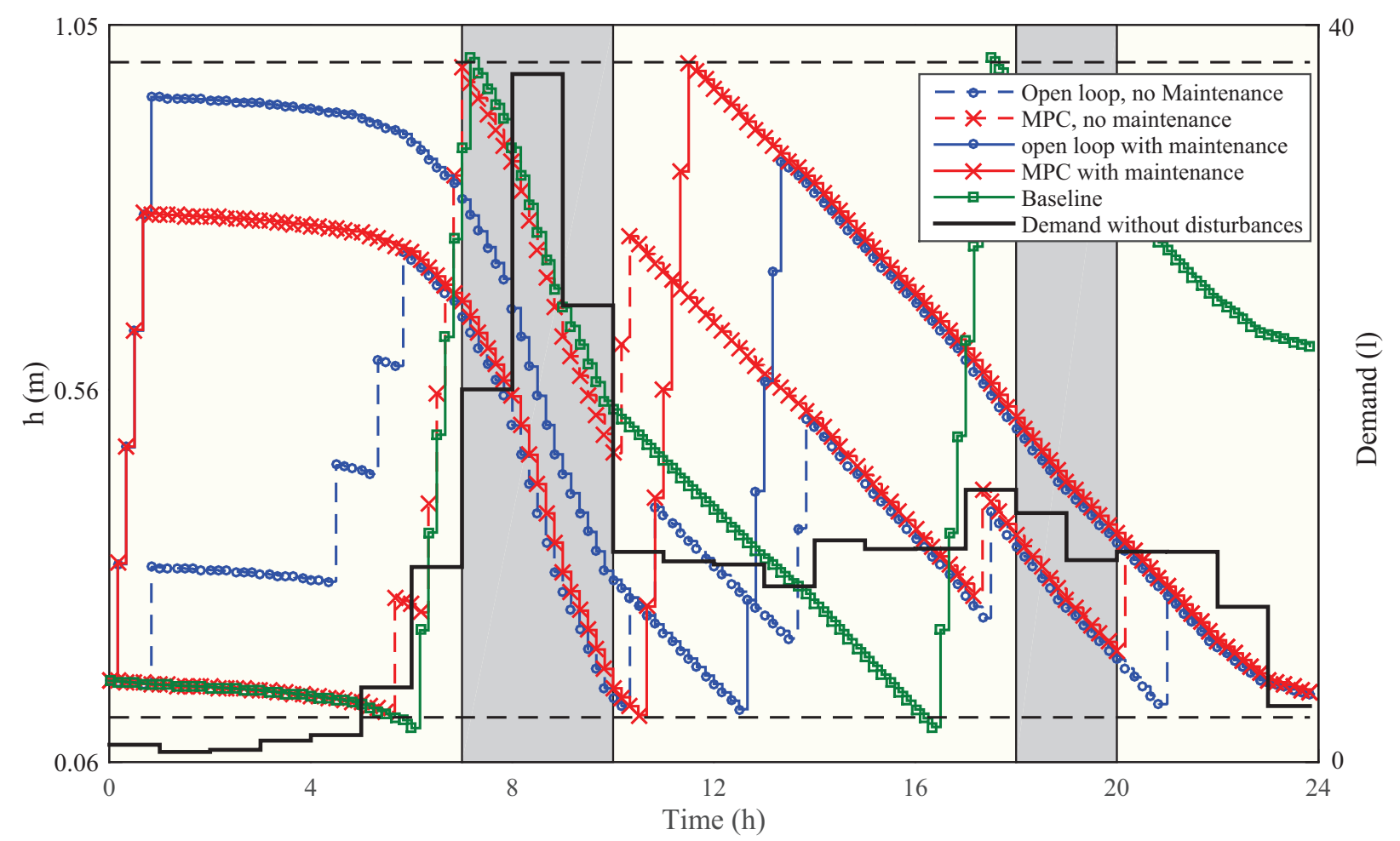

Figure 4: Water level in the tank without disturbance.

switches the pump on starting at $05: 30$. This is after the water level in the tank declined to 0.13 $\mathrm{m}$ due to the early demand in the house. The pump is switched on twice before the peak time where the tank is filled. This water is used up during the peak time with the level declining to 0.47 $\mathrm{m}$ before the pump is switched on at 10:00 hours, just after peak time, for a duration of $10 \mathrm{~min}$. Thereafter, the pump is switched on twice, for a duration of $10 \mathrm{~min}$ each, causing the rise of water level in the tank at 17:20 and 20:10 hours. Unfortunately, these two schedules are undesirable for the operation of the pump.

When the open loop optimal model with maintenance (Figure 3c) is considered, the two switching regimes at 00:10 and 12:40 hours, each lasting 50 minutes lead to the increase in the water level in the tank to $0.95 \mathrm{~m}$ and $0.87 \mathrm{~m}$ respectively. This water is sufficient to meet the demand in the house without violating the constraints. Identically, the closed-loop MPC model (Figure 3d) has two switching regimes at 00:00 and 10:30 hours, 40 minutes and 1 hour long respectively. They lead to a water rise in the tank to 0.80 and $1 \mathrm{~m}$ respectively. Thereafter, when the pump is off, this water level declines due to the demand in the house. It is also important to note that all the schedules were terminally constrained to also ease in comparison as seen in the graph.

\subsection{Control models with disturbance}

The models are tested for robustness using two likely disturbances to be experienced in dealing with water demand. First, a random disturbance throughout the horizon is applied and then a sudden spike in water demand is used. 


\subsubsection{Random disturbance}

Random disturbance can be caused by errors in accurately predicting the water demand, measuring the water level in the tank or inaccuracies of the pump's flow rate. By applying the random error signal, $\varepsilon(j)$, affecting the demand such that the new demand is,

$$
D_{\text {tot }}^{d}(j)=D_{t o t}(j)+\varepsilon(j)
$$

This demand in turn, affects the state equation (25). In this paper, the error signal is randomly generated as $\pm 50 \%$ of the demand, signifying a very inaccurate system. Figure 5 shows the com-

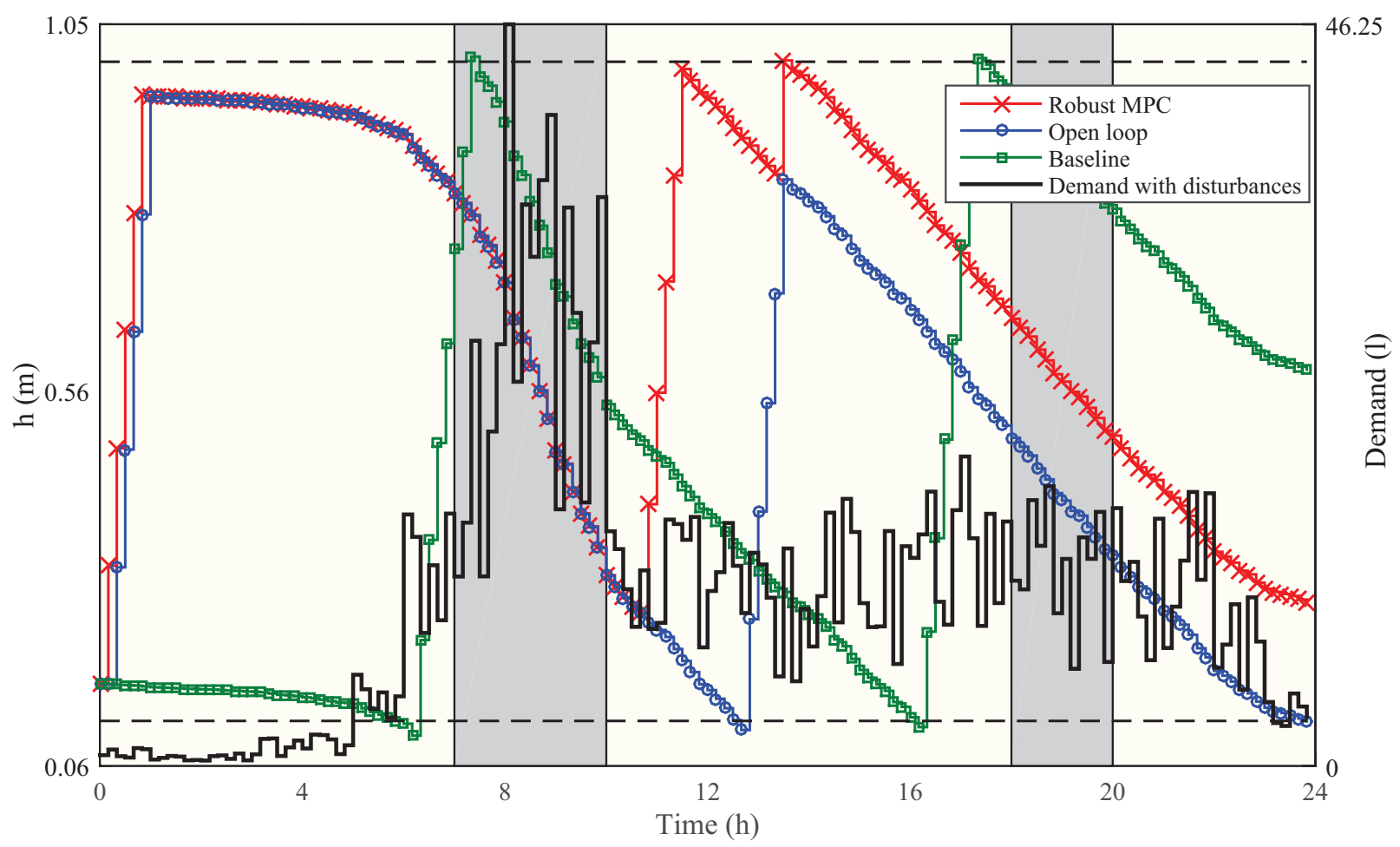

Figure 5: Water level in the tank with random disturbances.

parison of the water level in the tank with such a disturbance. Since the disturbance signal is randomly generated, the figure shows the average variation of the water level while using the two models. The open loop model does not violate the boundary constraints in most cases. Even in the cases where the open loop model violated the constraints, the violation was not very severe. Further, the MPC model switches on the pump at 10:00 hours for 10 minutes in order to deal with the disturbances. This extra switching also causes more water to be left in the tank. In order to ensure the MPC model remained feasible, the terminal constraint is implemented as a soft constraint taking note of the increase of the height of water in the tank when the pump is switched on during one sampling interval. The open loop and the MPC models incur pumping cost of 0.84 and 0.92 Rands respectively. This means that, in dealing with random disturbances arising from system inaccuracies, the open loop optimal control model is better than the MPC, as it is cheaper to implement and also incurs less running costs. 


\subsubsection{Sudden spike in water demand}

A sudden increase in water demand could be caused either by more people in the house during some period, or some unforeseen demand for water. In this paper, we assumed that the water demand suddenly increased by $70 \%$ between 18:00-20:00 hours. Figure 6 shows the comparison

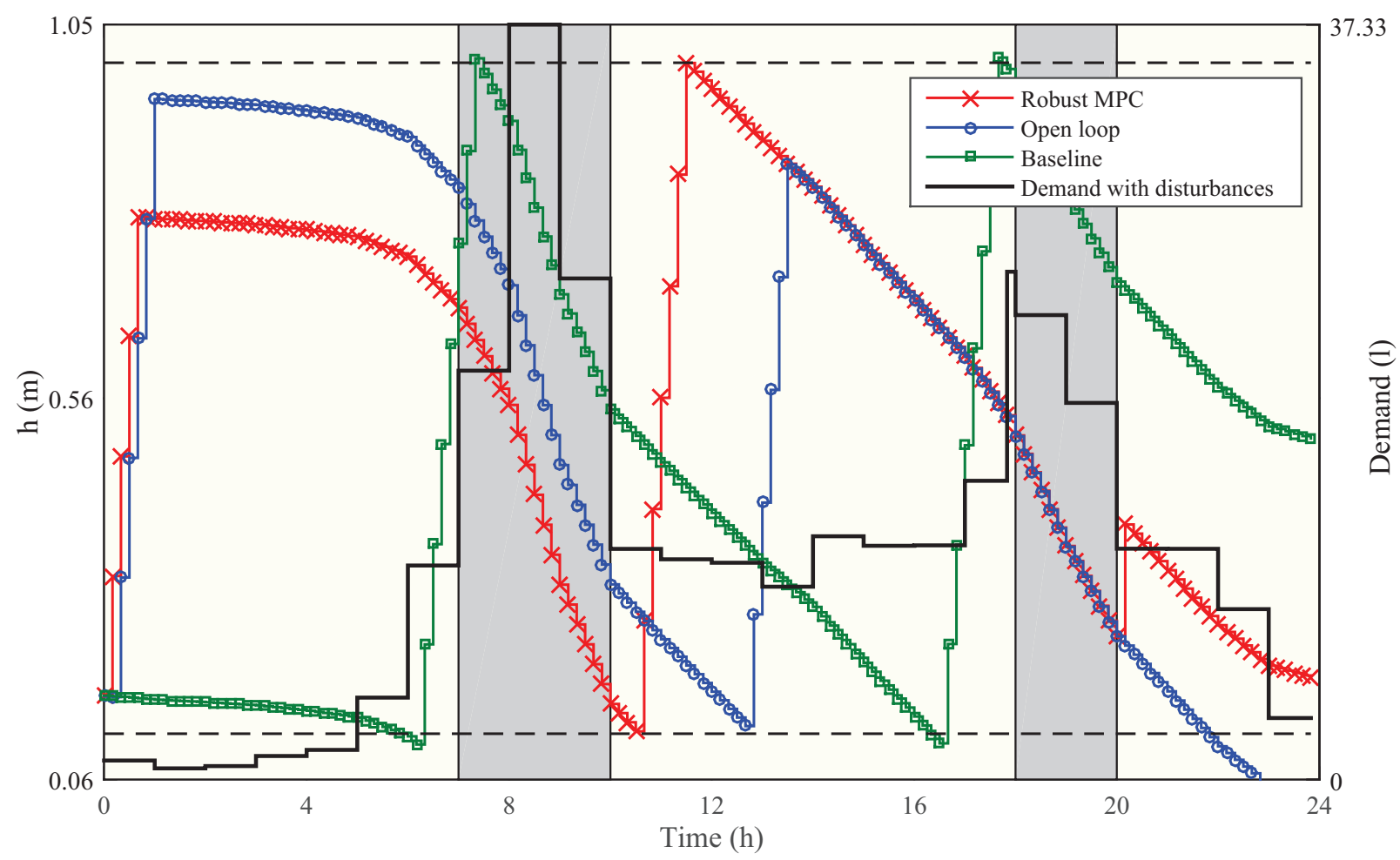

Figure 6: Water level in the tank with sudden increase in demand between 18:00-20:00 hours.

of the robust MPC and the open loop optimal control in the presence of disturbances. The open loop control model does not react to the unforeseen increase in demand. This leads to the emptying of the tank towards the end of the day effectively meaning the end-users would not have water to use. On the contrary, the MPC model reacts to the increased demand by switching on the pump at 20:10 hours for just 10 minutes. The extra water pumped in this duration means that the tank has enough water to meet the rest of the demand. The MPC model, however, incurs a pumping cost of 0.92 Rands against 0.84 Rands incurred by the open loop optimal model. Although the cost of using the MPC is slightly higher, it is more robust in dealing with sudden disturbances and it is more reliable in ensuring that the end-users always have water.

\subsubsection{Turnpike phenomenon}

During implementation, the open loop optimal controller does not guarantee proper operation in subsequent days as the water level in the tank at the end of the control horizon, which will be the initial state for the following day, is not always the same as $h(0)$ as seen in Figure 4, This problem is called the turnpike phenomenon [58]. Turnpike property has been described by Faulwasser et al. [59] as the phenomenon where the optimal solution in many finite-horizon optimal control 
problems for different initial conditions approach the purlieus of the best steady state but might leave it towards the end of the control horizon. This phenomenon has been observed in optimization problems with and without terminal constraints. The closed-loop MPC automatically corrects this problem over several days as it uses the previous state in the tank instead of the initial state. Since the sampling in this paper is done every $10 \mathrm{~min}$, one day has 144 samples. Therefore, from

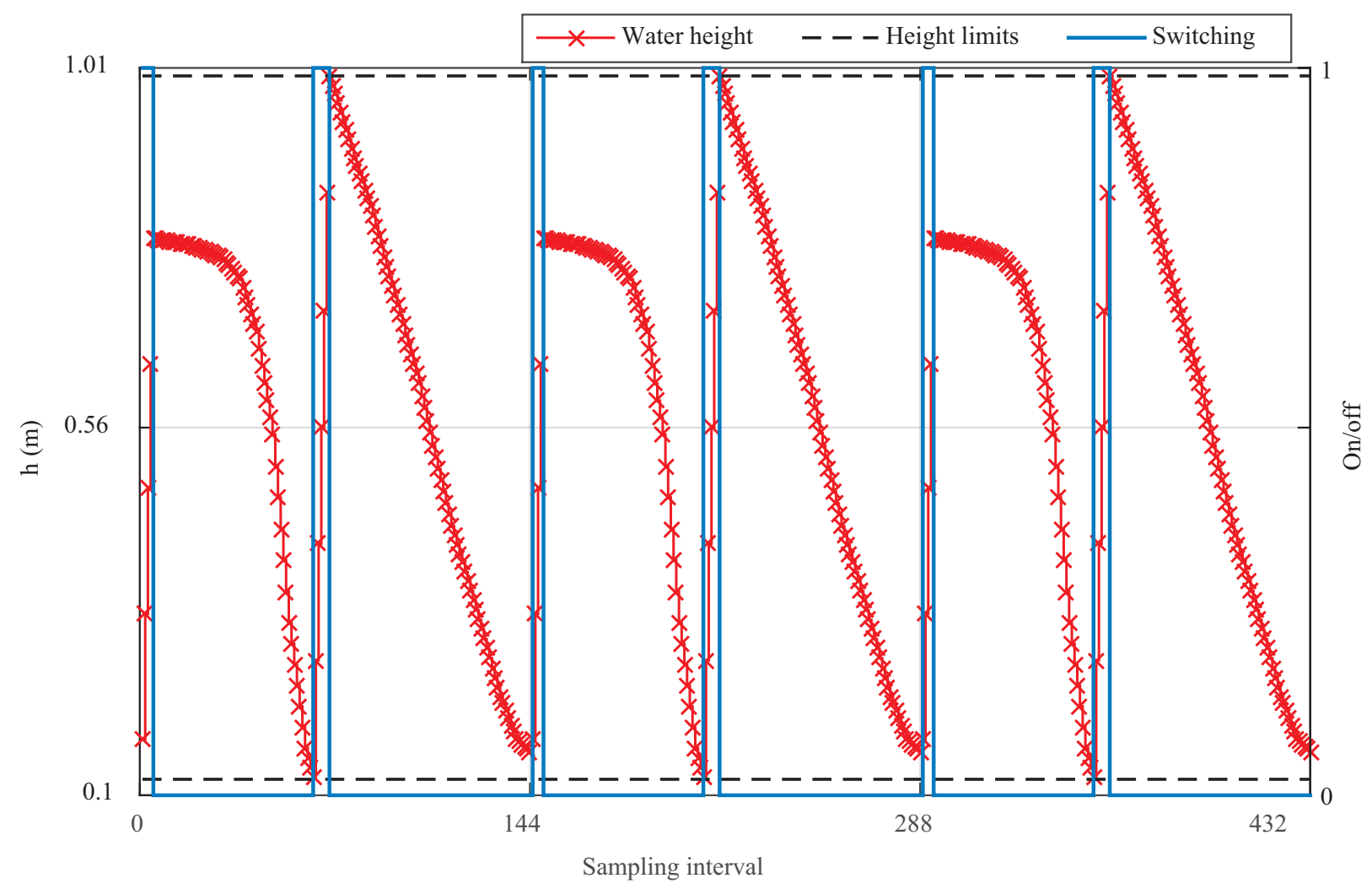

Figure 7: MPC switching and water level variation for 3 days.

Figure 7, the water level in the tank at the end of each day is the same, at a height of $0.15 \mathrm{~m}$. The advantages of the MPC to handle constraints and disturbances while possessing closed-loop stability and robustness makes it suitable for use in practical problems [60].

\subsection{Discussion}

The open loop and MPC models considering the maintenance cost of the pump are suitable for optimally controlling the pump to meet the household water demand. Both can save up to $48.5 \%$ of the pumping energy cost with respect to the baseline assuming there are no disturbances. However, this is never the case in reality. The open loop optimal model is suitable in cases where the only disturbances are due to the measurements errors, such that demand pattern doesn't change significantly. This is because while it still efficiently controls the pump, it incurs $8.7 \%$ less cost than the MPC model and it is cheaper to implement.

However, in reality, disturbances due to measurements uncertainties are not the only disturbances. There are instances when the house will either have more or less occupants, or need more 
water to perform some chores that are not performed daily, hence it is not possible to predict. The open loop model is unable to respond to such kind of a disturbance, leading to emptying of the tank even before the horizon is over. This model also runs at the danger of spilling the water if the demand unexpectedly goes down when it was already pumping the water. To mitigate against such disturbances, the MPC model has proved its robustness by adapting accordingly while ensuring that none of the constraints are violated. This robustness is at the expense of $9.5 \%$ more cost of energy than the open loop model, though it can still save $43.6 \%$ with respect to the baseline. Therefore, the robustness of the MPC model makes it more suitable in pumping the water to meet household water demand. In South Africa, the TOU period for different seasons was reviewed in 2015 where winter peak periods start one hour earlier ${ }^{6}$. The MPC model, when tested in both summer and winter periods, yields the same results indeed showing its robustness. If a different tariff is used, the MPC would automatically adopt to it to ensure the pump is efficiently operated.

Table 1 shows the comparison of the energy costs incurred by the two models as compared to the baseline model. The cost incurred in the baseline model is constant throughout because for the

Table 1: Comparison of the cost of pumping energy incurred

\begin{tabular}{lccc}
\hline & \multicolumn{3}{c}{ Pumping energy cost (Rands/day) } \\
\cline { 2 - 4 } & Baseline & Open loop & Robust MPC \\
\hline No disturbance & 1.63 & 0.84 & 0.84 \\
Random disturbance & 1.63 & 0.84 & 0.92 \\
Spike disturbance & 1.63 & 0.84 & 0.92 \\
\hline
\end{tabular}

day chosen, the baseline model doesn't need to pump extra water whether there are disturbances or not, since enough water is left in the tank at the end of the day. Similarly, since the open loop model is unable to predict and adapt to the disturbances, it also incurs the same energy cost in the three cases. However, the robust MPC model's cost of pumping energy increases by $9.5 \%$ due to the disturbances that necessitate the model to switch on the pump for an extra sampling interval in response to the disturbances. It is also noted that the extra switching pumps enough water to counter both types of disturbances, hence the same cost in the presence of disturbances.

Both the open loop model and the robust MPC model can potentially lead to a cost saving of $48.5 \%$ and $43.6 \%$ respectively. The open loop model therefore leads to higher cost saving, and is suitable in situations where only random disturbances are present. However, in practical situations, the demand for water in the house is bound to change, either rise or drop, without prediction. The ability of the robust MPC model to adapt to such a disturbance, unlike the open loop model, makes it superior although at a slightly higher cost.

The two control models are applicable in situations with unreliable municipal water supply that forces end-users to pump and store water such as cities in developing nations. This would enhance energy efficiency through load shifting translating to lower electricity cost to the end-users while ensuring reliability and convenience. The models are also useful for end-users using boreholes as their source of water. In the case where water rationing exists, the models would be fed with

6 WWW. eskom.co.za 
the time water is available so as to optimally control the pump. In scenarios where end-users have more than one source of water, for example, stored rain water or bore hole and municipal sources. In such cases, the models can be modified to accommodate the extra sources of water in ensuring energy efficiency and reliability by means of properly modelling the new system with extra components.

\section{Conclusion}

The increasing population and urbanization in developing nations is increasing pressure on existing energy and water infrastructure causing insufficient and unreliable supply to end users. Some of these end-users are forced to install water tanks in their houses to pump and store the water for use. The pumping increases the load on the power utilities in the same economies where the energy security is very low. In South Africa, for instance, the energy demand management has steadily been developing, while leaving out the energy-water demand management among domestic end users. This paper, therefore, presents the introductory research for energy-water nexus demand management in urban houses through optimal operation.

Open loop optimal and closed-loop MPC models are developed to meet the water demand in the house while minimizing the energy cost for pumping the water in the house. The models are developed using the TOU tariff in South Africa. Both models can potentially lower the energy cost by upto $48.5 \%$ when the demand is correctly predicted with no disturbances. This is never the case in reality and therefore the robust MPC control model proves suitable in dealing with all the disturbances, while still saving upto $43.6 \%$ of the energy cost. The open loop model can still be used in cases where the only disturbances present are due to random errors arising from measurements and the demand profile doesn't change that much. If widely adopted, the models would lead to lower energy costs to the consumers through lower electricity bills. Further, shifting the peak load would improve the stability of the grid by shaving the peak. This in turn would mean that some black outs experienced during peak time would cease as the demand from the grid would not be more than its capacity.

Further research will involve optimal controls for water conservation strategies within households. The research can also be furthered to commercial buildings in developing nations where the water needs to be pumped and stored. Energy efficiency can further be enhanced through the incorporation of renewable energy to power the pump. This will lead to more economic benefits to the end-users.

\section{Acknowledgements}

The authors would like to thank the National Hub for Energy Efficiency and Demand Side Management (EEDSM) for supporting this research.

\section{References}

[1] S. H. Jeong, R. Gulbinas, R. K. Jain, J. E. Taylor, The impact of combined water and energy consumption eco-feedback on conservation, Energy and Buildings 80 (2014) 114-119. 
[2] G. Boccaletti, M. Grobbel, M. Stuchtey, The business opportunity in water conservation (special report: The water imperative), McKinsey \& Company, Inc 2010 (2010) 67.

[3] G. Bonvin, A. Samperio, C. L. Pape, V. Mazauric, S. Demassey, N. Mazi, A heuristic approach to the water networks pumping scheduling issue, Energy Procedia 75 (2015) $2846-2851$.

[4] S. Pachauri, An analysis of cross-sectional variations in total household energy requirements in India using micro survey data, Energy policy 32 (15) (2004) 1723-1735.

[5] D. Setlhaolo, X. Xia, Combined residential demand side management strategies with coordination and economic analysis, International Journal of Electrical Power \& Energy Systems 79 (2016) 150-160.

[6] E. M. Malatji, J. Zhang, X. Xia, A multiple objective optimisation model for building energy efficiency investment decision, Energy and Buildings 61 (2013) 81-87.

[7] Z. Wu, X. Xia, B. Wang, Improving building energy efficiency by multiobjective neighborhood field optimization, Energy and Buildings 87 (2015) 45-56.

[8] H. Tazvinga, B. Zhu, X. Xia, Optimal power flow management for distributed energy resources with batteries, Energy Conversion and Management 102 (2015) 104-110.

[9] S. M. Sichilalu, X. Xia, Optimal power dispatch of a grid tied-battery-photovoltaic system supplying heat pump water heaters, Energy Conversion and Management.

[10] S. Chen, B. Chen, Urban energy-water nexus: A network perspective, Applied Energy.

[11] M. Talebpour, O. Sahin, R. Siems, R. Stewart, Water and energy nexus of residential rainwater tanks at an end use level: Case of australia, Energy and Buildings 80 (2014) 195-207.

[12] C. Cheng, Study of the inter-relationship between water use and energy conservation for a building, Energy and Buildings 34 (3) (2002) $261-266$.

[13] A. Gu, F. Teng, Y. Wang, China energy-water nexus: Assessing the water-saving synergy effects of energysaving policies during the eleventh five-year plan, Energy Conversion and Management 85 (2014) 630-637.

[14] C. Cheung, K. Mui, L. Wong, Energy efficiency of elevated water supply tanks for high-rise buildings, Applied Energy 103 (2013) 685-691.

[15] B. Baisa, L. W. Davis, S. W. Salant, W. Wilcox, The welfare costs of unreliable water service, Journal of Development Economics 92 (1) (2010) 1-12.

[16] R. Porter, The economics of water and waste in three African capitals, Ashgate, 1997.

[17] A. du Plessis, T. Harmse, F. Ahmed, Quantifying and predicting the water quality associated with land cover change: a case study of the blesbok spruit catchment, South Africa, Water 6 (10) (2014) 2946-2968.

[18] K. Menyah, Y. Wolde-Rufael, Energy consumption, pollutant emissions and economic growth in South Africa, Energy Economics 32 (6) (2010) 1374-1382.

[19] P. J. Ashton, D. Hardwick, C. Breen, M. Burns, A. Weaver, Changes in water availability and demand within South Africa's shared river basins as determinants of regional social-ecological resilience, Burns, MJ \& Weaver, AvB (2008) 279-310.

[20] B. Sonjica, Water conservation and demand management strategy for the water services sectors, Tech. rep., Department of Water Affairs and Forestry, South Africa (August 2004).

[21] H. Jacobs, L. Geustyn, B. Loubser, Water-how is it used at home?, in: Proceedings of the Water institute of Southern Africa, 2006, pp. 1-12.

[22] H. Jacobs, L. Geustyn, B. Loubser, B. Van Der Merwe, Estimating residential water demand in Southern Africa: technical paper, Journal of the South African Institution of Civil Engineering 46 (4) (2004) p-2.

[23] P. W. Mayer, W. DeOreo, Residential end uses of water, Aquacraft, Inc, Water Engineering and Management, Boulder, $\mathrm{CO}$.

[24] M. Heinrich, Water End Use and Efficiency Project (WEEP): Final Report, Branz, 2007.

[25] M. Loh, P. Coghlan, Domestic water use study in Perth, Western Australia, 1998-2001, Water Corporation Perth, Australia, 2003.

[26] P. Roberts, Yarra Valley Water: 2004 residential end use measurement study, Yarra Valley Water Melbourne, Australia, 2005.

[27] S. Nair, B. George, H. M. Malano, M. Arora, B. Nawarathna, Water-energy-greenhouse gas nexus of urban water systems: Review of concepts, state-of-art and methods, Resources, Conservation and Recycling 89 (2014) 1-10. 
[28] R. Malik, Water-energy nexus in resource-poor economies: the indian experience, International Journal of Water Resources Development 18 (1) (2002) 47-58.

[29] A. S. Vieira, E. Ghisi, Water-energy nexus in low-income houses in brazil: the influence of integrated on-site water and sewage management strategies on the energy consumption of water and sewerage services, Journal of Cleaner Production 133 (2016) 145-162.

[30] H. Zhang, X. Xia, J. Zhang, Optimal sizing and operation of pumping systems to achieve energy efficiency and load shifting, Electric Power Systems Research 86 (2012) 41-50.

[31] M. A. Jiménez-Bello, A. Royuela, J. Manzano, A. G. Prats, F. Martínez-Alzamora, Methodology to improve water and energy use by proper irrigation scheduling in pressurised networks, Agricultural Water Management 149 (2015) 91-101.

[32] B. Barán, C. von Lücken, A. Sotelo, Multi-objective pump scheduling optimisation using evolutionary strategies, Advances in Engineering Software 36 (1) (2005) 39-47.

[33] Y. A. Sha'aban, B. Lennox, D. Laurí, PID versus MPC performance for siso dead-time dominant processes, IFAC Proceedings Volumes 46 (32) (2013) 241-246.

[34] Š. Kozák, From PID to MPC: Control engineering methods development and applications, in: 2016 Cybernetics Informatics (K I), 2016, pp. 1-7.

[35] D. Q. Mayne, J. B. Rawlings, C. V. Rao, P. O. Scokaert, Constrained model predictive control: Stability and optimality, Automatica 36 (6) (2000) 789-814.

[36] R. Qi, H. Mei, C. Chen, F. Qian, A fast MPC algorithm for reducing computation burden of mimo, Chinese Journal of Chemical Engineering 23 (12) (2015) 2087-2091.

[37] S. Abirami, Z. hussain, S. Muthu, A. kumar, Performance comparison of different controllers for a level process, Int. Journal of Engineering Research and Applications 4 (3) (2014) 341-344.

[38] A. Li, Comparison between model predictive control and pid control for water-level maintenance in a two-tank system, Master's thesis, University of Pittsburgh (2010).

[39] B. Cirak, Comparision of MPC and PID controls of sirnak water supply network system, IJSRST 2 (1) (2015) 28-36.

[40] E. M. Wanjiru, X. Xia, Energy-water optimization model incorporating rooftop water harvesting for lawn irrigation, Applied Energy 160 (2015) 521-531.

[41] O. Pozos, C. A. Gonzalez, J. Giesecke, W. Marx, E. A. Rodal, Air entrapped in gravity pipeline systems, Journal of Hydraulic Research 48 (3) (2010) 338-347.

[42] M. Genius, E. Hatzaki, E. Kouromichelaki, G. Kouvakis, S. Nikiforaki, K. P. Tsagarakis, Evaluating consumers willingness to pay for improved potable water quality and quantity, Water Resources Management 22 (12) (2008) 1825-1834.

[43] P. F. Boulos, Z. Wu, C. H. Orr, M. Moore, P. Hsiung, D. Thomas, Optimal pump operation of water distribution systems using genetic algorithms, in: American Water Works Association Distribution System Symposium, Denver, Colorado, Citeseer, 2001, pp. 1-10.

[44] A. M. Bagirov, A. Barton, H. Mala-Jetmarova, A. Al Nuaimat, S. Ahmed, N. Sultanova, J. Yearwood, An algorithm for minimization of pumping costs in water distribution systems using a novel approach to pump scheduling, Mathematical and Computer Modelling 57 (3) (2013) 873-886.

[45] J. Naoum-Sawaya, B. Ghaddar, E. Arandia, B. Eck, Simulation-optimization approaches for water pump scheduling and pipe replacement problems, European Journal of Operational Research.

[46] M. Behandish, Z. Wu, Concurrent pump scheduling and storage level optimization using meta-models and evolutionary algorithms, Procedia Engineering 70 (2014) 103-112.

[47] T. Mathaba, X. Xia, J. Zhang, Analysing the economic benefit of electricity price forecast in industrial load scheduling, Electric Power Systems Research 116 (0) (2014) 158 - 165.

[48] B. Numbi, J. Zhang, X. Xia, Optimal energy management for a jaw crushing process in deep mines, Energy 68 (2014) $337-348$.

[49] D. Setlhaolo, X. Xia, J. Zhang, Optimal scheduling of household appliances for demand response, Electric Power Systems Research 116 (2014) $24-28$.

[50] S. J. Qin, T. A. Badgwell, A survey of industrial model predictive control technology, Control engineering practice 11 (7) (2003) 733-764. 
[51] A. Bemporad, F. Borrelli, M. Morari, et al., Model predictive control based on linear programming- the explicit solution, IEEE Transactions on Automatic Control 47 (12) (2002) 1974-1985.

[52] A. J. Van Staden, J. Zhang, X. Xia, A model predictive control strategy for load shifting in a water pumping scheme with maximum demand charges, Applied Energy 88 (12) (2011) 4785-4794.

[53] L. Wang, Model predictive control system design and implementation using MATLAB $囚$, Springer Science \& Business Media, 2009.

[54] R. Willis, R. A. Stewart, P. Williams, C. Hacker, S. Emmonds, G. Capati, Residential potable and recycled water end uses in a dual reticulated supply system, Desalination 272 (1) (2011) 201-211.

[55] L. Zhang, X. Xia, J. Zhang, Improving energy efficiency of cyclone circuits in coal beneficiation plants by pump-storage systems, Applied Energy 119 (0) (2014) 306 - 313.

[56] X. Zhuan, X. Xia, Optimal operation scheduling of a pumping station with multiple pumps, Applied Energy 104 (2013) $250-257$.

[57] D. Setlhaolo, X. Xia, Optimal scheduling of household appliances with a battery storage system and coordination, Energy and Buildings 94 (2015) $61-70$.

[58] M. Gugat, E. Trélat, E. Zuazua, Optimal neumann control for the 1d wave equation: finite horizon, infinite horizon, boundary tracking terms and the turnpike property, arXiv preprint arXiv:1505.05017.

[59] T. Faulwasser, M. Korda, C. N. Jones, D. Bonvin, On turnpike and dissipativity properties of continuous-time optimal control problems, arXiv preprint arXiv:1509.07315.

[60] J. Zhang, X. Xia, A model predictive control approach to the periodic implementation of the solutions of the optimal dynamic resource allocation problem, Automatica 47 (2) (2011) 358-362. 